Artigo Original

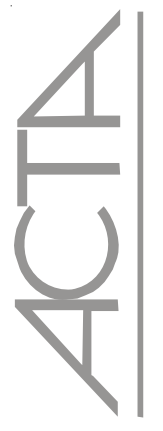

\title{
Como escolher o que não se conhece? Um estudo da imagem do enfermeiro por alunos do ensino médio*
}

\author{
How can one choose what is unknown? A study on the image of nurses by high school students \\ ¿Cómo escoger lo que no se conoce? Un estudio de la imagen del enfermero por alumnos de la \\ enseñanza medio
}

\section{Lígia Fahl Kemmer', Maria Júlia Paes da Silva ${ }^{2}$}

\begin{abstract}
RESUMO
Objetivo: Este estudo procurou aprofundar a compreensão das representações sociais sobre o enfermeiro e a Enfermagem por alunos do ensino médio, uma vez que estes estão em momento de escolha profissional. Métodos: Estudo de natureza qualitativa, baseado na teoria das Representações Sociais de Moscovici. Entrevistaram-se cinco alunos de uma escola particular na cidade de Londrina e, para análise, utilizouse o método de Discurso do Sujeito Coletivo. Resultados: As análises indicaram representações de pouca valorização, desconhecimento da formação educacional, dos campos de atuação, das possibilidades da profissão e sua autonomia. Discussão: As ancoragens das representações vêm da associação da atuação do enfermeiro exclusivamente ao âmbito hospitalar. Conclusão: É fundamental que se transmita o que os enfermeiros fazem, suas competências e campos de atuação, para o alcance de jovens adolescentes.

Descritores: Papel do profissional de enfermagem; Pesquisa qualitativa; Comunicação
\end{abstract}

\begin{abstract}
Objective: The purpose of this study was to understand further point of views of high school students regarding social representation of the discipline of nursing and professional nurses, given the fact they are phasing into career choice decisions. Methods: This qualitative study was guided by Moscovici's theory of social representation. The sample consisted of five high school students from a private high school. Data from interviews were submitted to discourse analysis. Results: The findings suggest that the discipline of nursing and professional nurses are undervalued by high school students; and, they lack knowledge about nursing educational requirements, working areas and opportunities, and professional autonomy. Discussion: Representations of the discipline of nursing and professional nurses might be associated with the fact that nurses work exclusively in hospitals. Conclusion: It is very importance to educate high school students about what nurses do, their competences, and working areas and opportunities.
\end{abstract}

keywords: Nurse's role; Qualitative research; Comunication

\section{RESUMEN}

Objetivo: Este estudio procuró profundizar la comprensión de las representaciones sociales sobre el enfermero y la Enfermería por alumnos de enseñanza media, cuando éstos se encuentran en el momento de la elección profesional. Métodos: Se trata de un estudio de naturaleza cualitativa, basado en la teoría de las representaciones sociales de Moscovici. Se entrevistaron a cinco alumnos de una escuela particular en la ciudad de Londrina y, para el análisis, se utilizó el método del Discurso del Sujeto Colectivo. Resultados: Los análisis indicaron representaciones de poca valorización, desconocimiento de la formación educativa, de los campos de actuación, de las posibilidades de la profesión y su autonomía. Discusión: Los anclajes de las representaciones vienen de la asociación de la actuación del enfermero exclusivamente al ámbito hospitalario. Conclusión: Es fundamental que se transmita lo que hacen los enfermeros sus competencias y campos de actuación, para alcanzar a los jóvenes adolescentes.

Descriptores: Papel del profesional de enfermería; Investigación cualitativa; Comunicación

\footnotetext{
* Trabalho temático da Disciplina Saúde do Adulto do Programa de Pós-Graduação da Escola de Enfermagem da Universidade de São Paulo - USP.

${ }^{1}$ Professora Assistente do Departamento de Enfermagem da Universidade Estadual de Londrina - UEL - Londrina (PR), Brasil; Pós-graduanda da Escola de Enfermagem da Universidade de São Paulo - USP - São Paulo (SP), Brasil.

${ }^{2}$ Professora Titular da Escola de Enfermagem da Universidade de São Paulo - USP - São Paulo - São Paulo (SP), Brasil.
} 


\section{INTRODUÇÃO}

O jovem adolescente cursando, o ensino médio vê-se diante de um momento de escolha profissional, que se configura em um momento crítico de mudança na vida do indivíduo acarretando conflitos relacionados à entrada no mundo adulto em relação à ocupação. Para um adolescente, definir o futuro não é somente definir o que fazer, mas, fundamentalmente, definir o que ser e, ao mesmo tempo, definir quem não $\operatorname{ser}^{(1)}$.

A decisão profissional do adolescente é fortemente influenciada pelas representações que possui a respeito das diferentes profissões, ancoradas ao longo de sua vida pelas experiências pessoais, influências sociais, econômicas e pelas imagens transmitidas pelos meios de comunicação, que se consubstanciam na imagem que possui de determinada carreira profissional. Essa imagem tem uma significação explicitada pelas representações sociais:

Entendemos por imagem profissional uma rede de representacões sociais que, por meio de um conjunto de conceitos, afirmaçoes e explicaçoes, reproduz e é reproduzida pelas ideologias originadas no cotidiano das práticas sociais, internas/externas a ela. A imagem profissional remete-nos à própria identidade profissional, em sua intrincada rede de significados que se pretendem exclusivos e, portanto, inerentes àquela profissão. A imagem profissional se consubstancia, assim, na própria representação da identidade profissional ${ }^{2)}$. (2:34).

Pesquisas que avaliam representações sociais da Enfermagem denunciam uma representação desatualizada e depreciadora da profissão ${ }^{(3-6)}$. Estudos realizados com diferentes estratos da população identificaram representações referentes à invisibilidade do enfermeiro, que é caracterizado por realizar tarefas simplesmente técnicas ${ }^{(4)}$, subordinado à área médica ${ }^{(5)}$, identificado como auxiliar de médico e atuando em uma profissão denotativa de mão-de-obra barata ${ }^{(6)}$. Essas representações podem ser partilhadas pelo jovem adolescente, uma vez que são também emergentes do contexto social de que ele faz parte ${ }^{(1)}$.

As profissões da área da saúde, conquanto sabidamente necessárias em sua articulação para que possam assistir ao ser humano em sua totalidade, apresentam status sociais díspares. Estudo avaliando o prestígio profissional do enfermeiro detectou que este profissional ocupa a sétima ou a oitava posição em termos de prestígio dentre treze profissões, enquanto a de médico ocupa a primeira posição nas escalas obtidas pelos métodos utilizados ${ }^{(7)}$.

Ao mesmo tempo, essa imagem está em descompasso com as transformações que, embora de maneira paulatina, e para alguns, ainda incipiente, inegavelmente têm refletido na prática social da Enfermagem nas últimas décadas. Tais mudanças acenam para cenários mais promissores, que se descortinam para a profissão neste milênio ${ }^{(8)}$.
Pergunta-se, entretanto, como e se essas transformações têm repercutido na imagem que o jovem adolescente possui a respeito da Enfermagem, uma profissão que, através do cuidado, visa melhorar a qualidade de vida em todos os ciclos existenciais do ser humano, em um país onde o acesso ao cuidado à saúde ainda é desigual, e a demanda pelo cuidado somente tende a aumentar.

Torna-se imprescindível, portanto, primeiramente, compreender quais são as representações do jovem adolescente sobre o enfermeiro, como tal imagem se forma e chega até ele, uma vez que essas representações são decisivas para a escolha ou não de determinada profissão, sendo este o objetivo deste estudo. Semelhantemente, espera-se que, a partir dessas reflexões, possa-se repensar o posicionamento e visibilidade do enfermeiro perante jovens que tenham interesse pela área da saúde.

\section{MÉTODOS}

Optou-se por utilizar um estudo transversal descritivo com abordagem qualitativa, baseado na teoria das Representações Sociais de Moscovici ${ }^{(9)}$. Participaram do estudo cinco alunos do terceiro ano do ensino médio, estudantes de uma mesma escola particular na cidade de Londrina - Paraná, tendo como critério de inclusão o interesse e/ou intenção de seguir a área da saúde. Todos os entrevistados eram do sexo feminino, de classe média, cujos pais possuíam nível educacional superior, e pretendiam prestar vestibular para medicina, fisioterapia, psicologia, odontologia ou farmácia. Os alunos foram contatados de forma aleatória, fora do âmbito escolar, para que não se sentissem coagidos a participar, em locais escolhidos pelos participantes.

Obteve-se a permissão para a pesquisa junto ao Comitê de Ética em Pesquisa do Hospital Universitário Regional Norte do Paraná e o Termo de Consentimento Livre e Esclarecido foi assinado pelos participantes. Utilizou-se, para a entrevista, um roteiro com dados demográficos como idade, sexo, intenção de carreira a ser seguida e as perguntas norteadoras: Qual sua imagem da Enfermagem? Qual sua imagem do enfermeiro? De onde vem essa imagem?

Como referencial para análise dos discursos, utilizou-se o Discurso do Sujeito Coletivo, que pode ser descrito como

um modo legítimo não por certo o único de conceber as Representações Sociais, entendendo-as como a expressão do que pensa ou acha determinada população sobre determinado tema. Este pensar, por sua vez, pode manifestar-se, dentre outros modos, através do conjunto de discursos verbais emitidos porpessoas dessapopulação ${ }^{(10)}$.

Os discursos foram primeiramente transcritos e 
submetidos à análise descritiva. Para tanto, utilizaram-se quatro figuras metodológicas: a ancoragem, a idéia central, as expressões-chave e o discurso do sujeito coletivo ${ }^{(10)}$. Fez-se a interpretação dos dados pela seleção das principais ancoragens e/ou idéias centrais presentes em cada um dos discursos individuais e em todos eles reunidos, terminando numa forma sintética, em que se buscou a reconstituição discursiva da representação social da imagem do enfermeiro e da Enfermagem.

\section{RESULTADOS}

A reconstituição dos discursos coletivos possibilitounos visualizar algumas representações sociais que alunos do ensino médio têm sobre o enfermeiro e a Enfermagem, as quais nos chamam a atenção:

1) O enfermeiro, como profissional pouco valorizado; auxiliar de médico e cumpridor de ordens terapêuticas, e a enfermagem uma profissão que lida com sofrimento; o desconhecimento da categorização da profissão.

Os jovens identificam a presença do enfermeiro associando-a a uma função essencialmente hospitalar, como dando continuidade à terapêutica prescrita pelo médico, mas também como alguém que permanece ao lado do paciente:

"Olha, eu fui uma vez, no hospital com minha avó, fiquei lá com ela... e assim,... o médico ele ia uma ver assim, ele falava o que ela tinha, ele consultava ela... mas quem cuidava, quem ela chamava eram sempre os enfermeiros... O médico vai lá... O médico passa uma vezpor dia... num horário, vai lá visitar... não sei dizer muito bem assim... mas tem, ele vai lá, conversa e dá o remédio e... TA! Agora, o enfermeiro vai lá... tem que tá dando assistência assim... toda hora, ele fica lá...” (DSC 1)

Nota-se que o encontro dos jovens estudantes com conceitos de saúde e doença ainda se dá através das experiências de terceiros, ainda que próximos de seu âmbito afetivo. Em relação ao enfermeiro, fazem alusão à baixa remuneração e à relação com o sofrimento, atribuidos à função de cuidar:

"É... uma pessoa que trabalha muito, eu acho". e que tem um rendimento às vezes muito pouco pelo seu trabalho... às vezes não, mas acho que tem, né? (o enfermeiro) é ele que vai lá... pega a coisa mais feia... assim... da área... não sei”. (DSC 3)

"Acho uma profissão tão linda... mas não seria uma opção para mim porque eu não nasci com esse dom de ficar lá com a pessoa, de sofrer junto com a pessoa... eu não tenho esse dom, mas acho uma profissão muito bonita. Eu vejo a enfermagem como uma profissão que lida com o sofrimento. A fisioterapia também, mas eu acho uma coisa mais amena que a enfermagem por estar no hospital, onde as pessoas estão doentes. Eu vejo a fisioterapia já como uma recuperação... a enfermagem não" (DSC 5)
Entre alunos que optam por cursos voltados para a área da saúde, em um momento pautado pela busca sobre profissões, não há nem mesmo o conhecimento de que o enfermeiro necessita ter curso superior, como ilustrado pelo discurso a seguir:

"O enfermeiro precisa estudar... [fazendo um som de indecisão] Ihh... eu preciso te dizer que eu não sei muito bem dados... né... assim... mas... é... eu acho que... ahh...eu acho que... ai, caramba, você me pegou... ehhh... praticamente o que.. o... que o médico estuda? Ah, eu não sei!! é meio complicado... [pensativa] porque tem auxiliar Ahh... tem que, tem que... ter uma faculdade... mas, ah [lembrandose] tem os enfermeiros que são auxiliares, não é isso? [risos] ai, caramba.. .Como quero essa área [da saúde] devia estarprocurando saber mais sobre isso... mas não sei mesmo..." (DSC4)

2) A ancoragem dessas representações vindo basicamente de experiências que associam o enfermeiro quase exclusivamente ao âmbito hospitalar, através de experiências com parentes hospitalizados, contatos pessoais com profissionais enfermeiros e pela mídia.

A ênfase detectada na identificação de uma atuação essencialmente hospitalar do enfermeiro vem de seus contatos e vivências com parentes hospitalizados:

"Minha imagem do enfermeiro? Vem do hospital... ahbh... sempre que a gente vai num hospital... a primeira coisa que a gente vê... enfermeiro é assim... em UTI também, sempre assim, ajudando... sempre com o paciente [risos] Ah, não sei, tipo parentes que já ficaram em hospitais, a minha avó... e tinha os enfermeiros tendo que aplicar remédios... eu ia visitar... Eu fui no hospital e en ficava sempre observando... eu fui no hospital com a mulher que trabalha em casa que é minha segunda mãe, assim... e teve e também meu avô... ele teve problema... então, eu sempre vou lá e é sempre o enfermeiro que está lá...." (DSC6)

As tarefas puramente técnicas no ambiente hospitalar - como a administração de medicamentos — são prontamente identificadas pelos jovens como definidoras da função do enfermeiro:

"Auxiliar os médicos, acho... ahh.... dar medicamentos, o médico atende e dai encaminha pra o enfermeiro fazer o que ele prescreveu no hospital... É porque o medico não vai poder estar ali pra fazer os negócios, então precisa do enfermeiro pra fazer. (DSC2)

O contato pessoal com amigos que cursam ou cursaram Enfermagem e atuam na área hospitalar também contribui para a construção dessa imagem:

"Minha prima faz Enfermagem... a gente conversa bastante... eu acho muito interessante... Bom, tem uma mãe de uma amiga minha, ela é enfermeira, então às vezes ela contava para a gente alguns casos... no hospital, que ela ficava morrendo de dó... "(DSC8) 
3) $\mathrm{O}$ desconhecimento das possibilidades dos campos de atuação do enfermeiro, de suas ações na prevenção e reabilitação da saúde e sua autonomia e considerações sobre a mídia.

Destaca-se nos discursos encontrados a identificação da atuação do enfermeiro, quase que com exclusividade, na área hospitalar:

"Acho que em hospitais, assim... em clínicas, algumas especializadas... Em hospitais... [risos] Não imagino em outro lugar... [Boa risada] No hospital!! [com ênfase] No bospital... não sei de mais nenhum lugar..."(DSC14)

Conquanto a atuação do enfermeiro ainda se concentre grandemente na área curativa, temos observado particularmente com a introdução do modelo de assistência preconizado pelo Sistema Único de Saúde um esforço significativo de atuação na área de prevenção, saúde da família, cuidado domiciliar, atuação em consultórios de Enfermagem e nas comunidades. Observa-se, entretanto, que, mesmo nos momentos em que os alunos identificam outros campos de atuação do enfermeiro, essa percepção é parcial, fragmentada e cheia de dúvidas:

"Humm... No hospital... em clinicas também às vezes encontra... Hummm... deixa-me ver, tem atendimento domiciliar também, que eu já vi... não sei... o enfermeiro... trabalha em tudo!! Ahh... tem enfermeiro na escola, no hospital, empresas... dar aula - (pode? Pode, né... você dá aula... [risos] Todas as áreas, né...? Pode ser, dependendo... bummm .. ajuda no parto, também??? [Risada] Acho que mais ou menos igual o médico, só que não tem especialização... ou tem...?? não sei, acho que não...” (DSC14)

Além disso, os jovens desconhecem as diversas especialidades possíveis dentro do campo da Enfermagem e traçam, novamente, uma ligação direta de dependência entre a atuação do enfermeiro e o médico:

"[Falando sobre os campos de atuação para o enfermeiro] no Brasil...?? Tem hospital, né? Um enfermeiro não tem como abrir uma clínica pra ele... por que... ele é muito geral... assim.. um médico tem como se especializar: pode ser um cardiologista, um neurologista, uma coisa assim... O enfermeiro não! [O enfermeiro trabalha]... na UTI... e em consultórios, dependendo, né... de médico que é..."(DSC16)

Mesmo quando identificam um campo diverso do hospitalar, como no caso da atuação da Enfermagem do Trabalho e como empresário, o discurso do jovem adolescente é cheio de dúvidas:

"Eu não sei [o que ele far. nas empresas], porque assim... numa empresa tem sempre risco de alguém se machucar, e tem que estar ali pra... receitar... Ah, não sei, acho que pra área de saúde mesmo... se alguém se corta, se alguém se machuca. Uma amiga disse pra mim que o enfermeiro na empresa do pai dela [de esterilização]... na empresa do pai dela tem um enfermeiro... [perguntando para a pesquisadora] Agora, qual a grande diferença entre o médico e o enfermeiro? Eu não sei... tem enfermeiro na empresa... [chegando a uma conchusão... E não tem médico... Por que um enfermeiro, né? Por quê? Então... talvez... um enfermeiro é um pouco um psicólogo... [risos] Não sei, não sei o que ele faz lá na empresa." (DSC15)

Observa-se que o adolescente sente a necessidade da busca de informações sobre as profissões. Pelos relatos, observa-se, entretanto, que é mínima, por vezes inexistente, a percepção dos jovens sobre a exposição dos profissionais enfermeiros através da mídia:

"No dia do enfermeiro aparecem aquelas propagandas, coisa e tal... [risos] ... mas outro lugar?? Na televisão... Tem filme também de quando vai pra guerra, essas coisas... Ahh.. não sei...!! O que en vi na televisão? Propaganda do dia do enfermeiro, que eu tinha falado, ai aparecem as enfermeiras... de branco, coisa e tal... ai tem a Cruz. Vermelha... acho que é assim..." (DSC9)

Em uma geração cibernética e conectada em rede, chama a atenção a posição que a internet assume como fonte de recursos para informação sobre as futuras profissões:

"Busco informaçoes] Na internet.. é mais rápido o acesso....A maioria dos livros estão desatualizados, se a gente não puder confiar na Internet..!!. Naquele guia do estudante, en também procuro bastante, eu também procuro conversar com os profissionais da área que eu conheço, incomodando, perguntando... "(DSC17)

\section{DISCUSSÃO}

Pela análise dos discursos encontrados, observa-se que o trabalho do enfermeiro é associado ao sofrimento e a uma atividade com pequena remuneração, além de estar intrinsecamente associado a uma atividade puramente curativa e hospitalar. Os adolescentes desconhecem a atuação do enfermeiro nas áreas de promoção, resolução e prevenção, recuperação da saúde e defesa pela qualidade de vida ${ }^{(8)}$.

A imagem que se configura da associação a um pequeno rendimento e à definição de atuação com ações reputadas de menor valor podem não atrair um jovem hoje, que se vê diante de um leque de profissões com nomes modernos e instigantes.

Essa imagem, indubitavelmente, foi construída socialmente em decorrência de questões históricas relacionadas a pontos fundamentais para a produção dessas representações no imaginário coletivo. Dentre elas, destacam-se questões de gênero, intimamente relacionadas 
à profissão de enfermagem, enquanto majoritariamente feminina; relações de poder, em que a hegemonia médica foi perpetuada dentro da equipe multiprofissional; políticas de saúde privilegiando o modelo médico de assistência, a reafirmação de uma imagem subserviente através dos meios de comunicação de massa e uma invisibilidade perpetuada pelos próprios profissionais, entre muitos outros $^{(2,3,6,8)}$.

Distorções de imagem em relação às ocupações são suscitadas no adolescente que, muitas vezes, valoriza as profissões alheio à real função social delas. Torna-se fácil compreender que fatores culturais, valorativos de profissões que conferem status, poder e prestígio afetem o adolescente por relacionar-se e estar inserido em uma comunidade, uma vez que esses valores são um reflexo da ideologia dominante ${ }^{(1)}$.

Dessa forma, a tecnologia do cuidado e o valor da vida - o primeiro como expressão objetiva do fazer, e o segundo como sustentação moral do trabalho do enfermeiro $^{(8)}$ — não lhes parecem, à primeira vista, tão atraentes, como discutem alguns autores ${ }^{(11)}$ :

Parece-nos que a representação construida em torno do curar, do afastar a doenç, ambos considerados, nos tempos modernos, como atividades médicas, é de permanência simbólica muito mais significativa do que aquela construida em torno do cuidar do corpo doente ou sadio, atividade mais identificada à mulher e à enfermeira. A cura é um ato impregnado de mitos e simbologias, enquanto o cuidado é entendido como um ato banal e repetitivo do cotidiano feminino. ${ }^{(11: 28)}$

Representações de menor valia relacionadas ao cuidar, portanto, acabam por interferir na escolha que o adolescente faz quando considera optar pela área da saúde. Analisando o perfil de estudantes ingressantes no curso de Enfermagem, um estudo verificou um percentual de $76,9 \%$ de opção preferencial por outros cursos, constatando-se dificuldades de conhecimento ou identificação com a profissão, anteriores à pesquisa, resultantes de estereótipos e tabus culturais ${ }^{(12)}$.

De maneira paradoxal, o funcionamento do serviço médico, que é visível, valorado e notado nos discursos dos adolescentes, depende essencialmente da ação da Enfermagem, por meio da vigilância diuturna, continuidade dos procedimentos terapêuticos e planejamento e prestação de cuidados. Não obstante, observa-se que "quanto menor a autonomia do serviço de Enfermagem, mais pode este multiplicar a produtividade do ato médico"(13).

A motivação de alunos que escolhem Enfermagem como profissão sofre grande influência de amigos e familiares. Os jovens percebem a Enfermagem como um acesso à área da saúde, havendo pouco conhecimento da profissão em si. Discute-se, portanto, a importância de se divulgar as áreas de atuação da Enfermagem junto a essa população ${ }^{(14)}$.

A imagem de um grupo profissional ou profissão representada pela mídia é entendida, com freqüência, como medida significativa do valor social e econômico daquele grupo ${ }^{(15)}$. Dessa forma, a invisibilidade da Enfermagem e as imagens estereotipadas, muitas vezes encontradas na mídia ${ }^{(3)}$, pouco contribuem como informação ocupacional da profissão.

Em estudo realizado sobre a imagem do enfermeiro, detectou-se que os próprios profissionais de comunicação, que são intermediários na codificação das representações imagéticas e textuais sobre a sociedade, desconhecem os campos de atuação, mercado de trabalho e categorização profissional da Enfermagem, denunciam a invisibilidade do enfermeiro perante a mídia e a sociedade e alertam para a responsabilidade do próprio enfermeiro para que haja reconhecimento profissional e visibilidade ${ }^{(16)}$.

Uma vez que o adolescente não consegue visualizar as possibilidades de atuação e realização de uma determinada profissão, sua possibilidade de escolha por aquela carreira fica diminuída. Métodos mais eficazes deveriam ser adotados para alcançar possíveis estudantes, transmitindolhes o que os enfermeiros fazem, para que eles possam também considerar as vantagens da Enfermagem como carreira ${ }^{(17)}$.

Mesmo em um país com sérias desigualdades sociais como o Brasil, o crescimento de milhares de jovens deuse paralelamente à grande explosão das tecnologias da informação que, por sua vez, culminaram no advento da Internet. É marcante o poder de atração que esse novo espaço e essa nova realidade têm, particularmente junto aos jovens, para quem a tecnologia digital está tão integrada à vida como se fora um simples eletrodoméstico ${ }^{(18)}$. Vislumbra-se, aqui, uma mediação que não pode ser subestimada como veículo para atingir o jovem adolescente na comunicação sobre as possibilidades da enfermagem como carreira profissional.

\section{CONCLUSÃO}

O estudo das representações sociais contribui para a compreensão do conjunto de componentes e relações contidas no saber prático do senso comum coletivo. Para essa compreensão, é preciso responder a três perguntas fundamentais: quem sabe, e a partir de onde sabe? O que e como se sabe? Sobre o que se sabe, e com que efeito? ${ }^{(19)}$ A relevância de se buscar esta compreensão está no fato de que, fundamentalmente, as representações também nos orientam em relação às nossas decisões, pois agimos em função daquilo que representamos.

Diante dos discursos obtidos neste estudo, percebese uma lacuna entre os espaços ocupados pelo enfermeiro na atualidade, seu papel social e as representações que os adolescentes - cujo olhar e expectativas estão voltados 
para as possibilidades de escolha profissional — possuem da profissão. $\mathrm{Na}$ análise dos discursos encontrados, destaca-se que, pelo fato de o jovem adolescente visualizar essencialmente o hospital como campo de atuação para o enfermeiro, dentro de uma ação notadamente curativa e de apoio, essa imagem não está sendo desafiada.

O presente estudo trouxe algumas reflexões iniciais sobre a imagem que um grupo de adolescentes possui sobre o enfermeiro e a enfermagem e que podem orientar sua atitude em relação à profissão. Atentar para essas representações podem auxiliar-nos na elaboração de estratégias, visando minorar a invisibilidade da enfermagem como profissão junto a essa faixa etária.

\section{REFERÊNCIAS}

1. Bohoslavsky R. A informação ocupacional em orientação vocacional. In: Bohoslavsky R. Orientação vocacional: a estratégia clínica. 11a ed. São Paulo: Martins Fontes; 1998. p. 157-72.

2. Silva AL, Padilha MICS, Borenstein MS. Imagem e identidade profissional na construção do conhecimento em enfermagem. Rev Latinoam Enfermagem. 2002; 10(4): 586-95.

3. Sampaio MA. Enfermagem, mídia e bioética [tese]. Brasília: Universidade de Brasília; 2002.

4. Fernandes BM. A enfermeira no olhar das clientes: representações da sua prática profissional [tese]. Rio de Janeiro: Universidade Federal do Rio de Janeiro; 1998.

5. Furegato ARF, Prestupa SCM. O que a população sabe e o que espera do enfermeiro. Rev Gaúch Enferm. 1999; 20(1):80-90.

6. Santos CB. A imagem da enfermagem frente aos estereótipos: uma revisão bibliográfica. In: $8^{\circ}$ Simpósio Brasileiro de Comunicação em Enfermagem (SIBRACEN); 2002 Out 15-19; Ribeirão Preto. Anais. Ribeirão Preto; 2002.
7. Sousa FAEF, Silva JA. Prestígio profissional do enfermeiro: estimação de magnitudes e de categorias expandidas. Rev Latinoam Enfermagem. 2001; 9(6):19-24.

8. Leopardi MT, Santos I, Sena RR. Tendências de enfermagem no Brasil: tecnologias do cuidado e valor da vida. In: $51^{\circ}$. Congresso Brasileiro de Enfermagem; $10^{\circ}$. Congresso Panamericano de Enfermeria; 1999 Out 02-07, Florianópolis. Anais. Florianópolis; 1999.

9. Moscovici S. On social representations. In: Forgas JP, editor. Social cognition - perspectives on everyday understanding. London: Academic Press; 1981. p. 43-9.

10. Lefèvre F, Lefèvre AMC. O discurso do sujeito coletivo: um novo enfoque em pesquisa qualitativa; desdobramentos. Porto Alegre: EDUCS; 2003.

11. Pereira WR, Silva GB. A mulher, o trabalho e a enfermagem profissional: algumas reconsiderações sob a ótica do gênero. Texto \& Contexto Enfermagem. 1997; 6(1):18-32.

12. Cardoso NCS, Matos MFS, Vieira MJ. A opção pela enfermagem: estudo retrospectivo em Sergipe. Rev Bras Enfermagem. 2003; 56(6):640-5.

13. Batista SS, Barreira IA. A luta da enfermagem por um espaço na universidade. Rio de Janeiro: Anna Nery/UFRJ; 1997.

14. Spindola T, Moreira A. O aluno e a enfermagem: por que esta opção profissional? Esc Anna Nery Rev Enferm. 1999; 3(3):25-36.

15. Hallam J. Nursing the image: media, culture and professional identity. London; New York: Routledge; 2000.

16. Kemmer LF, Silva MJP. Um estudo sobre a visibilidade do enfermeiro segundo a percepção de profissionais de comunicação. Rev Latinoam Enfermagem. No prelo 2007.

17. Berliner H. Take a lesson from Hollywood! Nurs Stand. 2003;17(1): 8 .

18. Terencio MG, Soares DHP. A Internet como ferramenta para o desenvolvimento da identidade profissional. Psicol Estud. 2003; 8(2):139-45.

19. Jodelet D. Representações sociais: um domínio em expansão. In: Jodelet D, organizadora. As representações sociais. Rio de Janeiro: EdUERJ; 2001. p.17-44. 